\title{
EVALUATION AND DEVELOPMENT OF E-LEARNING TOOLS AND METHODS IN DIGITAL PHOTOGRAMMETRY AND REMOTE SENSING FOR NON EXPERTS FROM ACADEMIA AND INDUSTRY
}

\author{
E. Gülch ${ }^{\mathrm{a}}$, N. Al-Ghorani ${ }^{\mathrm{a}}$, B. Quedenfeldtt ${ }^{\mathrm{b}}$ J. Braun ${ }^{\mathrm{b}}$ \\ ${ }^{a}$ University of Applied Sciences Stuttgart, Department of Geomatics, Computer Science and Mathematics, \\ Schellingstr. 24, 70174 Stuttgart, Germany - eberhard.guelch@hft-Stuttgart.de,n.ghorani@hotmail.com \\ ${ }^{\mathrm{b}}$ Trimble Germany GmbH, Niederlassung Stuttgart, Rotebuehlstr. 81, 70178 Stuttgart - \\ (Barbara_Quedenfeldt,Josef_Braun)@Trimble.com
}

Commission VI, WG VI/2

\section{KEY WORDS: Learning, Training, Education, Developing countries, Software}

\begin{abstract}
:
There does already exist a wide variety of tutorials and on-line courses on Photogrammetry and Remote Sensing very often used in academia. Many of them are still rather static and tedious or target high-knowledge learners. E-learning is, however, increasingly applied by many organizations and companies for life-long learning (like e.g. the EduServ courses of EuroSDR), but also for training of resellers and in order to save the expenses and time of travelling. A new issue of this project when taking into account the ethnic mentality in some countries like Saudi Arabia where it is impossible to mix the females and males at any institution type or for instance to teach ladies by a male teacher face to face, many academic workshops have been done separately twice by foreign organizations to adapt this situation.

This paper will focus on these issues and present experiences gathered from a Master Thesis on "E-learning in Digital Photogrammetry and Remote Sensing for Non Experts using Moodle” at HFT Stuttgart in co-operation with a software vendor and a reseller and experiences from a current European Tempus IV project GIDEC (Geographic information technology for sustainable development in Eastern neighouring countries). The aim of this research is to provide an overview on available methods and tools and classify and judge their feasibility for the above mentioned scenarios. A more detailed description is given on the development of e-learning applications for Digital Photogrammetry and Remote Sensing using the open source package Moodle as platform. A first item covers the experiences from setting up and handling of Moodle for non-experts. The major emphasis is then on developing and analyzing some few case studies for lectures, exercises, and software training in the fields of Digital Photogrammetry and Remote Sensing. Feedback from students and company staff will be evaluated and incorporated in an improved design and sample implementation. A further focus is on free software and tools to allow an easy integration of dedicated methods as audio and video flashes, quizzes for self evaluation, dynamic training, web-conference, etc. into the e-learning platform. The overall objective is to evaluate on how far it is currently possibly to allow the non-experts from academic and non academic sectors to get the initial experience and knowledge in Digital Photogrammetry and Remote Sensing in a modern, flexible and economic way. The time and the skills required for developing web-based materials will thus be investigated in more detail. Additionally, the quality of the developed e-learning application will be assessed based on a list of quality criteria developed.
\end{abstract}

\section{INTRODUCTION}

In the last decades e-Learning has become an essential part at all education levels for institutions and companies with partly quite different needs. As of today "over 2,000 learning tools are available in the market; ranging from traditional course and content development tools through e-Learning collaboration and sharing tools as well as tools for personal learning. The tools are freeware, open source, and commercial" (Technologies, 2011). The need to manage content and users at institutions led to the development of Learning Management Systems (LMS) either commercial or open source.

There are already more than 250 providers of commercial LMS and over 40 open source LMS such like Moodle and are likely to gain a foothold in higher education sector (Carabaneanu, et al., 2006). LMS also represents the learning community itself in which learners can communicate and share information through forum, blogs, wiki etc.

Digital Photogrammetry and Remote Sensing (DPRS) disciplines have being integrated into many study programs such as geographic, environment, agriculture, architecture, civil engineering, etc. However, the available tutorials and online courses either are very static and tedious or they target the high knowledge learners. „There has been a lot of related work written and carried out in the general area of eLearning and slowly more and more projects are being carried out in photogrammetric and remote sensing areas. A lot of the projects that already exist, however, are more orientated towards GIS and do not specifically tackle the problems which surround eLearning in photogrammetry and remote sensing“ (Haig et al., 2004).

The industrial sector is also interested in e-Learning to provide online technical support or software training to their international resellers or customers. Moreover, many organizations use it for lifelong learning (e.g. the EduServ courses offered by EuroSDR (European Spatial Data Research, EuroSDR, 2012). It is however being observed, that most teaching personnel lacks extended programming skills to create learning materials that grab learners' interest and encourage them for further study. The conventional material is published 
is to to convert from MS documents such as MS Word or MS PowerPoint to static PDF files without animations.

In this research an investigation of e-Learning tools and methods (Fig. 1) is going to be achieved by creating different learning scenarios, including lectures, exercise, and software training in the context of DPRS. The contents are deliverable in different formats and can be used anytime and anywhere from the internet, locally on a PC, or even from Mobile devices. The major focus is on the ease of use, ability to exploit the existing learning resources, adherence to e-Learning standards, and ability to add a kind of interactivity. Another perspective of this research is to develop a LMS in which the DPRS learners can communicate or meet virtually in a real time for collaboration or online training. We have chosen Moodle (Modular ObjectOriented Dynamic Learning Environment) which is an open source LMS that enables creating powerful, flexible, and engaging online learning courses with a focus on interaction and collaborative construction of content (Moodle, 2012).

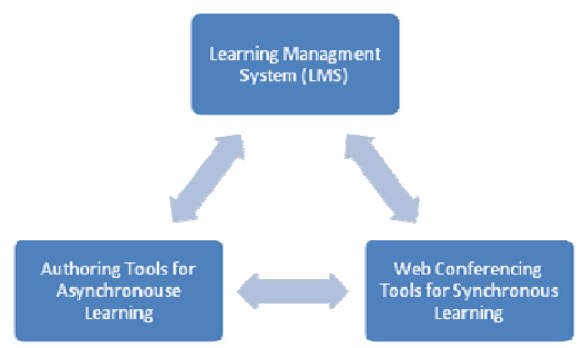

Figure 1. Overview of the methods and tools

The specific objectives are:

a) Evaluating available tools in asynchronous and synchronous e-Learning. Identifying the learning scenarios they fit, the time and skills required for developing the contents.

b) Developing a prototype e-Learning system in Moodle to allow learners from academia and non academic sectors to get the initial experience and knowledge in DPRS in a modern, flexible and economic way.

c) Assess the overall quality of the prototype system based on a developed criteria list.

\section{BACKGROUND}

e-Learning is essentially the computer and network-enabled transfer of skills and knowledge. E-Learning applications and processes include Web-based learning, computer-based learning, virtual education opportunities and digital collaboration. It can be self-paced or instructor-led and includes media in the form of text, image, animation, streaming video and audio (Wikipedia, 2011).

\section{$2.1 \quad$ E-Learning Generations}

e-Learning has been developed over the following three main generations (Karrer, 2007). e-Learning 1.0 was the first generation of e-Learning delivered through the web and managed using LMS. It usually supports courseware built using an authoring tool following a traditional training model. The content was delivered in asynchronous mode or using virtual classroom software. e-Learning 1.3 made learning available in the context of work, thus the contents should be in a form that is easily retrieved, not always through LMS, rather they are sent to the learner via emails or accessed through links on the organization's website. The learning content is developed more quickly using rapid authoring tools and delivered in small bits and pieces. With the emergence of Web 2.0, e-Learning 2.0 generation made the learning more collaborative. E-Learning 2.0 is based on tools that combine ease of content creation, web delivery, and integrated collaboration. It increased emphasis on social learning using social tools such as wiki, forum, blogs, and chat.

\section{$2.2 \quad$ Categories of e-Learning}

E-Learning falls into four categories, from the very basic to the very advanced. The categories are:

- Knowledge Databases: Knowledge databases offer indexed explanations and guidance for the user's questions. Examples are Google, Wikipedia, YouTube, Tweeter, Flicker, and software web based user guides.

- Online Support: It is a slightly more interactive form than knowledge databases. With online support one can interact with people through forums, chat rooms, e-mail, or live instant messaging applications. Online support offers the opportunity for more specific questions and immediate answers.

- Asynchronous Learning: It is a combination between the two previous e-Learning forms. It enables the learner to interact with other learners and the trainer, but does not necessarily require the learner to be in contact with any other learner or instructor at the time of learning.

- Synchronous Learning: Synchronous learning is done in real-time with a live instructor facilitating the training. Everyone logs in at a set time and can communicate directly with the instructor and with each other. This type of training usually takes place via Internet web sites, audio- or videoconferencing, Internet telephony, or even two-way live broadcasts to students in a classroom.

\subsection{Tools for different categories of e-Learning}

2.3.1 Content Authoring Tools for Asynchronous eLearning: Software applications used to create and package multimedia content deliverable for end users (Wikipedia, 2011). The subcategories of the content authoring tools are:

- Traditional e-Learning tools: These tools are designed for graphics artist, web designers, programmers, and instructional design experts. It typically takes a long to learn how to time to proficiently use these tools.

- Rapid e-Learning tools: These tools do not require specific design skills. The tools should be easy to use to allow e.g. SMEs (Small and Medium enterprises) rapid success.

- Simulation tools: These are the most complex authoring tools. Simulation contents need long time to be created (might be several months) and also a group of developers.

2.3.2 Web Conferencing Tools for Synchronous eLearning: These tools are used to host asynchronous eLearning sessions. They provide collaborative virtual class in which learners and teacher, regardless of their locations, interact with each other and with the learning content.

2.3.3 Social Tools: These tools support the informal personal learning, they enable individuals searching for and accessing all type of resources e.g. video, podcast, blogs, etc.

\subsection{Related work for DPRS}

There are few web based learning applications in DPRS which are considered a quite good source of information. In general,

Table 1: Examples of web-based learning applications 


\begin{tabular}{|c|c|c|c|}
\hline 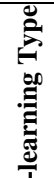 & $\begin{array}{lr}\text { Textbooks } & \text { with } \\
\text { rare animations } \\
\text { and low } \\
\text { interactivity }\end{array}$ & $\begin{array}{l}\text { Interactive } \\
\text { textbooks with quiz } \\
\text { at the end of most } \\
\text { tutorials for self } \\
\text { assessment. }\end{array}$ & $\begin{array}{l}\text { Developed web- } \\
\text { based Learning } \\
\text { Management } \\
\text { Systems (LMS). }\end{array}$ \\
\hline 苛 & $\begin{array}{l}\text { Remote Sensing } \\
\text { Core Curriculum } \\
\text { (RSCC) } \\
\text { http://www.r-s-c- } \\
\text { c.org/ }\end{array}$ & $\begin{array}{l}\text { Canadian Centre of } \\
\text { Remote Sensing } \\
\text { (CCRS). } \\
\text { (http://ccrs.nrcan.gc. } \\
\text { ca/resource/index_e. } \\
\text { php\#tutor) }\end{array}$ & $\begin{array}{l}\text { On demand courses } \\
\text { over the Internet } \\
\text { (e.g. JICA NET, } \\
\text { EuroSDR). } \\
\text { www.eurosdr.net }\end{array}$ \\
\hline
\end{tabular}

they are online textbooks with a certain level of interactivity. Table 1 lists some examples. However, these applications still lack very often dynamic content as well as active interaction with learners.

Some related works focus on using game-based approach: (Balz and Fritsch, 2008) developed SAR simulators for SAR image analysis that allows students examining thousands of SAR images to be able to recognize immediately the features of interest even with various SAR noising effects. (Fritsch, 2009) emphasizes the importance of exploiting the evolution in mobiles and communications technology. The Institute for Photogrammetry (ifp) - Universität Stuttgart has been using podcasting technique since 2006. The lectures, exercises and labs are provided in vodcast formats (video podcasts) using Tablet PC with recording software (Camtasia) for editing and producing the final video. The International Society for Photogrammetry and Remote Sensing (ISPRS) organizes a competition every two years to observe and promote the developments in e-Learning tools based on Computer Assisted Teaching CONtest (CATCON) and on the criteria of the shortterm project "Analysis of eLearning Software and Guidelines for Quality Assurance” (Katterfeld and König, 2008). The criteria are premised on the contents, didactics, learner context, software ergonomics, economical aspect, and technology and the evaluation is achieved using online questionnaire for reviewing e-Learning applications.

\section{EVALUATION OF AUTHORING TOOLS}

In this chapter, authoring tools are going to be evaluated by creating different content types in Remote Sensing and Photogrammetry. The contents include exercises, lectures notes, presentations, tests and quizzes for self assessment. The features of each tool and the time required to learn it are examined. The chapter concludes with an evaluation summary along with recommendations for using these tools.

According to (Fine, 2011) several major factors should be taken into account to choose the appropriate content authoring tool:

- $\quad$ Objectives and delivery method,

- Media,

- Interactivity,

- Interoperability and standards,

- Content longevity,

- $\quad$ Skills and time,

- Cost.

According to these factors, five authoring tools are explored by creating different learning contents in remote sensing and photogrammetry. The authoring tools are:

- eXe software: Open source software (eXelearning, 2011).

- Lectora ${ }^{\circledR}$ Inspire: Commercial software (Trivantis, 2010).

- Camtasia ${ }^{\circledR}$ Studio: Commercial software (TechSmith, 2012)

- iSpring Pro: Commercial software (iSpringSolutions, 2012)
- PowerFlashPoint Professional: Commercial software (De Rossi, 2011)

The evaluation of the five demonstrated authoring tools showed that they offer a variety of features fit for different needs and different delivery methods. It became obvious, that these tools are easy to use and no programming skills are required. The created contents by these tools are compatible with the standards in e-Learning, they can contain different types of rich media and are portable to any LMS. Table 2 compares the five authoring tools with respect to a set of features. Table 3 gives estimates on estimated learning time and output formats of the investigated authoring tools.

It is obvious that one of major factors for choosing the proper tool depends on the content type which itself defines whether it is an interactive or a passive content. For an assessment content (interactive), the user should work with a tool that supports questions and feedback; while creating a video content (passive) requires tools that support screen casting.

Camtasia is a rather suitable tool for creating video materials for software training, live presentation, and even for editing and publishing the recorded class videos. Learners often prefer screencasts because they get information pretty quickly and can play the video on mobile devices. Camtasia contents also enable on-the-go learning using Mobile devices.

Lectora is an authoring tool which is bundled with a group of other tools (Camtasia, Snagit, and flaypaper). A comprehensive authoring environment for creating and delivering multimedia content is provided. For more advanced contents the learning time is rather long, simple functionality is rather easy to develop. The costs are, however, rather high.

The eXe software provides rather intuitive, easy-to-use tools that enable creating and publishing e.g. software user manuals. It is very powerful to incorporate various media or hyperlinks to sources. Questions and feedback functionality is to a certain limit possible.

Table 2: Comparison between content authoring tools - I

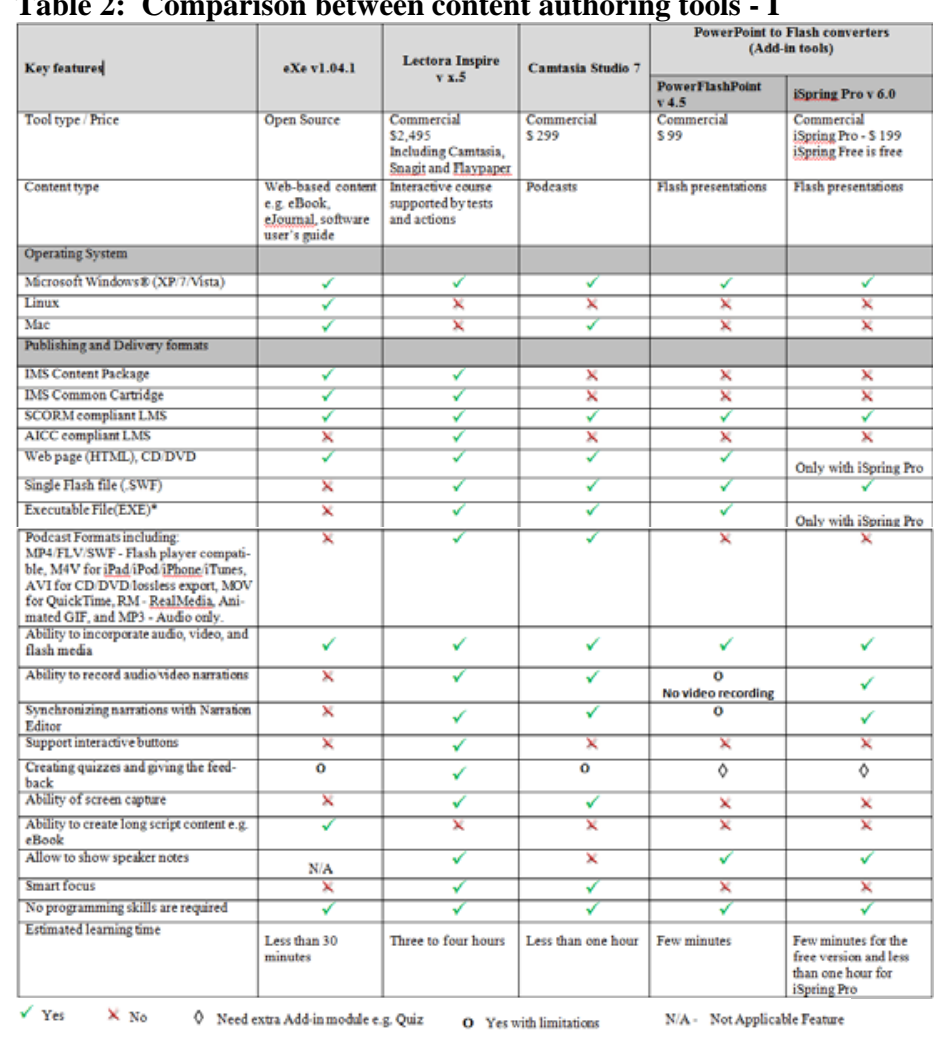


Table 3: Comparison between content authoring tools - II

\begin{tabular}{|c|c|c|c|c|}
\hline & eXe & Lectora Inspire & Camtasia & $\begin{array}{l}\text { PowerPoint- } \\
\text { to-Flash }\end{array}$ \\
\hline Product type & Open source & $\begin{array}{l}\text { Commercial } \\
(\$ 2500)\end{array}$ & $\begin{array}{l}\text { Commercial } \\
(\$ 300)\end{array}$ & $\begin{array}{l}\text { Commercial } \\
(\$ 100-\$ 200)\end{array}$ \\
\hline Content type & $\begin{array}{l}\text { Web-based } \\
\text { content e.g. } \\
\text { eBook, e.Journal, } \\
\text { software user's } \\
\text { guide }\end{array}$ & $\begin{array}{l}\text { Interactive } \\
\text { course } \\
\text { supported by } \\
\text { tests and actions }\end{array}$ & Podcasts & $\begin{array}{l}\text { Flash } \\
\text { presentations }\end{array}$ \\
\hline $\begin{array}{l}\text { Estimated learning } \\
\text { time }\end{array}$ & $<30$ minutes & 3.4 hours & $<1$ hour & rew minutes \\
\hline $\begin{array}{l}\text { Output format: } \\
\text { SCORM } \\
\text { CD/DVD } \\
\text { Web pages 'HTML' } \\
\text { Flash and EXE }\end{array}$ & $\begin{array}{l}\text { Yes } \\
\text { Yes } \\
\text { Yes } \\
\text { No }\end{array}$ & $\begin{array}{l}\text { Yes } \\
\text { Yes } \\
\text { Yes } \\
\text { Yes }\end{array}$ & $\begin{array}{l}\text { Yes } \\
\text { Yes } \\
\text { Yes } \\
\text { Yes }\end{array}$ & $\begin{array}{l}\text { Yes } \\
\text { Yes } \\
\text { Yes } \\
\text { Yes }\end{array}$ \\
\hline
\end{tabular}

The investigated PowerPoint to Flash converter tools can create passive contents unless a quiz creator is added. They have the advantage of quick usage of PowerPoint presentations and their combination with audio features. Working with narrations has shown to be easier in iSpring Pro than with the PowerFlashPoint tool.

\section{EVALUATION OF WEB CONFERENCING TOOLS IN SYNCHRONOUS E-LEARNING}

Web conferencing has become an integral part of the business and distance learning world besides the classical instance messaging or simple chat. Web conferencing tools allow its users to see, hear, text chat, present and share information (presentations, documents, videos, applications, and screens) in real time. Web conferencing tools enable members of organizations at different locations to connect easy and quick and to save time and costs of traveling. Learner and instructor can interact with each other and with the learning content, regardless of their locations. But web conferencing can not only replace face-to-face meetings, but also allows to share applications, and to assist in on-line software training and recording the sessions and publishing for later play-back.

Since our investigated LMS Moodle does not come with an incorporated web conferencing tool, several free third party modules can be integrated with Moodle such as Adobe Connect, BigBlueButton, Elluminate Live, and OpenMeetings. In this research the BigBlueButton (BBB) tool (BigBlueButton, 2010) is evaluated as a representative of open source tools. In addition two commercial web conferencing tools have been explored using online software training: Verishow (Verishow, 2012) and Cisco WebEX (Cisco, 2012). Both are SaaS (Software as a Service) tools, which do not require software installations. Users can access the meeting any PC or handheld with internet connection.

In cooperation with Trimble Germany a conference was conducted in Germany with five participants in Jordan from SMEs. A test has been achieved to measure the streaming quality and the participant's ability to follow the training instructions simultaneously with the presenter's voice when he shares his desktop. The recording capabilities and playback has been investigated as well. Table 4 summarizes a comparison of the most important tested features between $\mathrm{BBB}$ and the commercial tools.

BigBlueButton in the tested 0.8-Beta is quite comparable to the commercial web conferencing software especially with features like the ability to record and playback the conference session. The built-in VoIP feature (by clicking the headset icon) has a voice delay with an average of 2-4 seconds which can be accepted for many applications. In other commercial web conferencing tools, extra charges apply to enable participants to use VoIP service. For online software training that fully rely on desktop sharing, user can increase the efficiency by reducing the bit depth from 32 bit to 16 bit. BBB like Cisco WebEX allows passing control during the meeting to an attendee which is a useful functionality for collaborative training meetings that include more than one trainer. BBB is a good alternative for SMEs or small classes due to the quite high number of allowed attendees. However, the installation of BBB is not straight forward and many open source components need to be installed to enable the complete functionality.

\section{Table 4: Comparison of Web-Service tools}

\begin{tabular}{|c|c|c|c|}
\hline Feature & BigBlueButton & Verishow & Cisco WebEX \\
\hline Price & Free & $\$ 49 /$ month (basic level) & $\$ 49 /$ month (up to 25 users) \\
\hline Voicelag & $2-4 \mathrm{sec}$ & $\sim 4 \mathrm{sec}$ & Unnoticeable \\
\hline $\begin{array}{l}\text { Recording and } \\
\text { playback }\end{array}$ & $\begin{array}{l}\text { The recording runs } \\
\text { within HTML5 } \\
\text { browsers }\end{array}$ & $\begin{array}{l}\text { The voice in the recorded } \\
\text { session is not clear. }\end{array}$ & $\begin{array}{l}\text { Has it own recorder tool, } \\
\text { the recording is editable } \\
\text { and saved as -wrf file. } \\
\text { Runs by webex player }\end{array}$ \\
\hline VoIP calling & Free & Enabled on the Pro level & $\$ 0.09 / \mathrm{min} /$ attendee \\
\hline $\begin{array}{l}\text { Number of } \\
\text { Participants }\end{array}$ & $\begin{array}{l}\text { Up to } 25 \text { users or } \\
\text { more based on the } \\
\text { host sever } \\
\text { capabilities. }\end{array}$ & Is not defined & $1000 \sim 3000$ participants \\
\hline
\end{tabular}

\section{MOODLE AS LEARNING MANAGEMENT SYSTEM}

The sample learning contents created by the previous evaluated e-Learning tools (Synchronous and Asynchronous) are integrated with Moodle 2.1. A web server has been setup on a standard PC for testing the performance of the Moodle prototype system when it becomes online.

\subsection{Installing Moodle}

Typical Moodle users range from individual teachers to company training departments and universities. Each of them has different requirements with different level of complexity thus there are issues of great importance when selecting a host.

In our experience the installation of the Moodle server was rather straightforward and did not require very specific IT expertise.

5.1.1 Hosting with management and maintenance service: Moodle is a software package relies on a set of applications, including a web server (e.g. Apache), PHP, database engine (e.g. MySQL), and Moodle code. Some hosts offer Moodle as a full service package with Moodle upgrade, building the contents, database maintenance, backups, and technical support, etc. Moreover, these hosts provide and maintain the server that Moodle runs on. In general the cost of service depends the number of users, the assigned webspace, and on speific other features.

5.1.2 Hosting without management and maintenance service: This is the most common and inexpensive solution. The developed Moodle in this research was hosted by HostSo company at price of US\$25/year. Users with good level of skills select this option. They are able to manage and maintain the Moodle package. The companies that support this kind of host are responsible for providing hardware and the applications used to run Moodle but are not responsible for administrating and managing Moodle.

In our experience at least two major issues have to be checked before selecting the web hosting company. First, the right versions of PHP, for example, Moodle 2.1.1 needs PHP v 5.3.2 or later with memory limit at least $64 \mathrm{MB}$. Second, selection of the database management systems: Moodle needs MySQL v 5.0.25, Postgres 8.3, MSSQL 2005 or Oracle 10.2. 


\subsection{Integrating Moodle with e-Learning tools}

In this research Moodle formed the core platform for the integration of tools in an advanced LMS prototype (Fig. 2). The learning contents created using the authoring tools described above were published on the Moodle site. Two learning modes are available in this prototype: synchronous and asynchronous. The BigBlueButton module worked as a provider of virtual class from within Moodle for online software training. In addition links to free global data were given to serve the learners and let them deepen the acquired knowledge.

5.2.1 Courses: Courses are the spaces on Moodle where teachers add their learning materials. Two samples of courses were created for the purpose of this research: a Remote Sensing and a Photogrammetry course. Each course contains sample materials that have been created using the asynchronous tools described above. A definition part of the provided learning contents has been added such as the objectives, knowledge requirements, and learning outcomes.

5.2.2 Labs: Labs complement the lectures. Learners get a better understanding when they explore the knowledge they acquired by applying it on their own data. Restrictions in lab time for protected software often slow the learning progress. Many users would prefer open source software tool without such restrictions. For Remote Sensing several free tools are available. The developed lab in the Moodle prototype basically contains links to simple image viewers such like ERDAS Viewer or ER Viewer and some datasets. These viewers enable interpreting the images, work with bands combination, and understand the effect of resample methods, and simple image filtering. Free tools in photogrammetry are, however, still rare. As an example the E-Foto open source software (E-Foto, 2012) has been integrated. The E-Foto software allows working on image rectification, stereoscopic measurements, interior and exterior orientations. The software is enhanced by sample datasets and short videos for software training tutorials.

An interactive online calculator of flight planning parameters was easily customized using a SpreadsheetConverter tool.

5.2.3 Virtual Class Room: Since Moodle does not come with an incorporated web conferencing tool, BigBlueButton was integrated with Moodle prototype through a free plug-in. The authentication role in Moodle assigns the user role in BigBlueButton automatically. Each planed session is announced as an activity in the Moodle calendar block, and the recorded session is published as Moodle resource for playback.

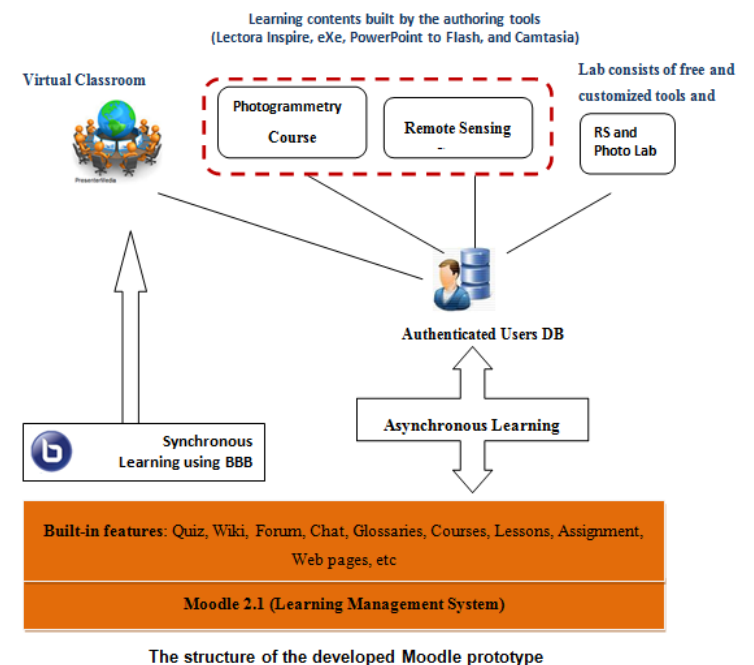

Figure 2: The structure of the developed Moodle prototype
5.2.4 Glossary: A glossary activity is added to Moodle prototype to enable learners creating lists of categorized definitions. Some entries are supported by pictures to add more explanation, like a photographic dictionary. A glossary can be a collaborative activity or be restricted to entries made by the teacher. In a Moodle course, using the auto-link feature, any word located in the glossary is highlighted.

\subsection{Evaluation of the Moodle Prototype}

In order to evaluate the overall quality of the developed Moodle prototype a questionnaire drawn from the criteria list by

Katterfeld and König (2008) had been used (Table 5). In cooperation with HFT students and InfoGraph's (InfoGraph, 2012) clients from academia and non-academic sectors, feedbacks of 25 users have been analyzed as shown in Fig. 3.

Table 5: Questionnaire for evaluating the prototype system (adopted from Katterfeld and König 2008))

\begin{tabular}{|l|l|}
\hline 1. User Type and Intensity of Use \\
\hline o $\quad$ User type, Intensity of Use, Which part(s) you worked on? \\
\hline 2. Content \\
\hline o $\quad$ Is the content correct?, Is the content complete? Appropriateness of material \\
\hline 3. Didactics \\
\hline o $\quad \begin{array}{l}\text { Are advanced functionalities for interaction available? Is assessment or } \\
\text { feedback given to exercises and tests? Are communication options to the } \\
\text { tutor and/ or to learners available? }\end{array}$ \\
\hline 4. Software Ergonomics \\
\hline o $\quad \begin{array}{l}\text { Do the content designs contribute to comprehensibility and are pleasant in } \\
\text { general? Is the user guided in a clear way? }\end{array}$ \\
\hline 5. Learner's Reaction \\
\hline o & How do you rate in overall this eLearning application \\
\hline
\end{tabular}

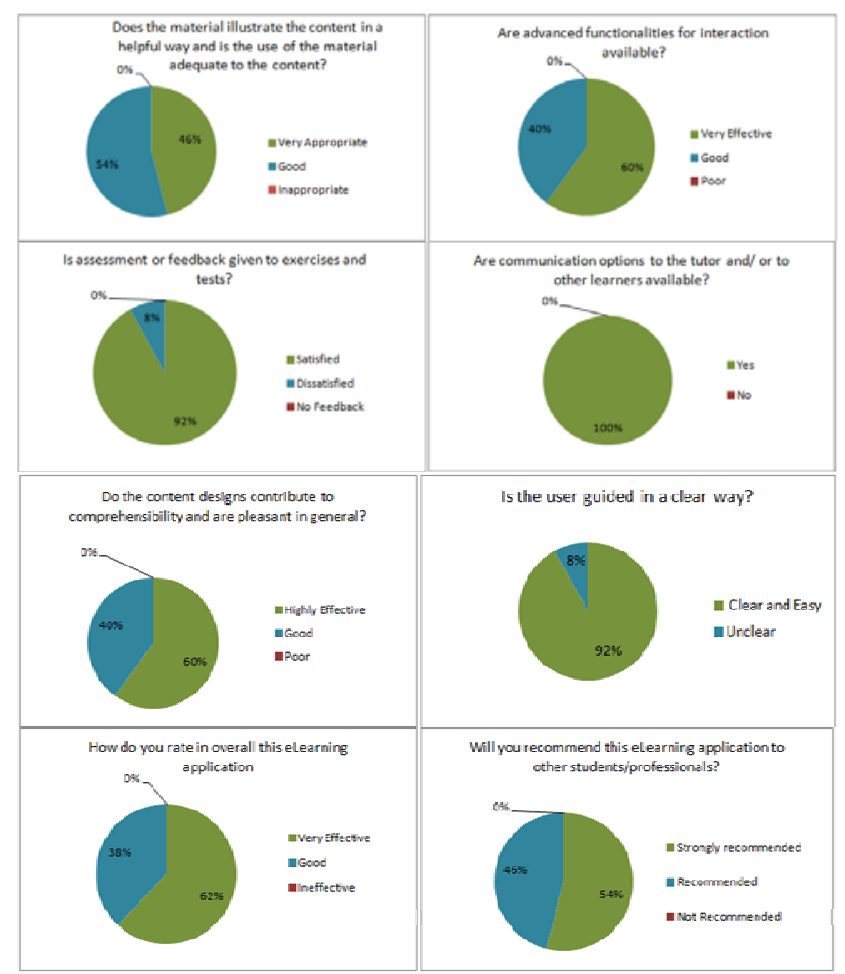

Figure 3: Feedback of 25 users for the Moodle LMS

The test persons judged the designed materials, using the previous authoring tools, as clear and illustrative. The users were able to view, interact with the contents online on the 
developed Moodle site and save them on their machines for offline usage. Providing printable version of the materials is regarded as important, and can be prepared as PDF files. However, the materials alone are obviously not enough, the script notes are also important for learners to augment their acquired knowledge. The navigation through the site to access the information is judged clear and easy. The provided feedbacks with the assessment tasks on Moodle site such as quizzes are generally satisfying, but can certainly be further improved. Users' feedbacks also show that the developed learning system was effective and highly recommended to be used by other learners; it enables them to communicate with each other for sharing knowledge using chat, forums, and wiki pages. A suggestion to add recorded videos of the live class for absent students needs to be considered in future, as well as adding more links to information sources.

\section{CONCLUSIONS}

The authoring tools used in this research for asynchronous eLearning are proved to be powerful for composing dynamic contents and supporting different types of media. The investigation showed that they are easy to use, no programming skills are required, and standards adherent which make the contents exchangeable. Despite the fact that selecting the authoring tool depends on the content type, there is no all-inone authoring tool which can meet the different needs in DPRS. Converting PPT to flash or podcast formats can be achieved by few clicks, the major component is the time of creating the original PPT. Adding video or audio narrations will need extra time especially with non-native speakers. In this research, a PPT of 25 slides was created in 8 9 hours without narration or test, the presentation includes many animations some of which took about one hour. Another example is creating five minutes screencast of short exercise about relief displacement (recorded PPT using Camtasia), the time for creating the PPT with the animations was less than one hour but recording and refining the audio narration took three hours. This time can be extremely reduced with more practice and experience. Creating an interactive material using Lectora software that contains 13 slides including action buttons in addition to one test of different question types took about 24 hours.

For synchronous e-Learning, the investigation showed that BigBlueButton is a very suitable tool and quite comparable to the commercial tools. The main drawback to BBB is its reliance on the existence of other components that will disable the related feature in case the component is not installed properly. Once the software is properly installed, starting meetings is straight forward. Using hosted web conferences on the vendor's server (SaaS) is extremely easy and accessible from everywhere. One can start or join the web meeting within few minutes and no software is installed.

Moodle, as an open source LMS, is easy to use and to customize and also provides dedicated built-in features for learning. The overall quality of the developed learning system showed a positive impact and high possibility to make learners from academia and non-academic sector being experts and nonexperts to get the initial knowledge in DPRS in a modern and economic way. There does, however, remain a need for more eLearning material especially in the field of Photogrammetry.

\section{REFERENCES}

Al-Ghorani, N. (2012). eLearning in Digital Photogrammetry and Remote Sensing Using Moodle. Master Thesis, HFT Stuttgart.
Balz, T., \& Fritsch, D. (2008). High-Performance SAR Simulation on Retail Video Gaming Consoles for Education and Training Purposes. Proceedings of ISPRS VI/1 \& VI/2 Workshop, XXXVII-B6a. Beijing.

BigBlueButton (2011). BigBlueButton Frequently Asked Questions. http://code.google.com/p/bigbluebutton/wiki/FAQ (January 2012)

Cisco (2012). Cisco WebEX. www.webex.com (January 2012).

Carabaneanu, L., Trandafir, R., Mierlus-Mazilu, I. (2006). Trends in E-learning. Tampere, FINLAND.

De Rossi, L. C. (2011). PowerPoint to Flash Conversion Tools Mini-Guide. http://fileformatconversion.masternewmedia.org/powerpoint_to_flash_conversi on_tools/

E-Foto (2012). E-Foto. http://www.efoto.eng.uerj.br/en (January 2012)

EuroSDR (2012). www.eurosdr.net (April 2012).

eXelearning. (2011). eXe, The eLearning XHTML editor. http://wikieducator.org/Online_manual (December 2011).

Fine, D. (2011). Choosing the Right Content-Authoring Tool For Your e-Learning Needs. (SyberWorks) http://www.syberworks.com/articles/ContAuthTool.htm (January 2012).

Fritsch, D. (2009). Podcast - A Worldwide Standard in Elearning. Proceedings of ISPRS VI/1 \& VI/2 Workshop on Tools and Techniques for E-Learning, XXXVIII-6/W7. Potsdam.

Haig, J., Wiggenhagen, M., \& Heipke, C. (2004). E-learning, Bringing Photogrammetry onto the Internet and Integrating it within Already Existing Courses. XX ISPRS Congress Istanbul, Commission I-VII, XXXV-6, p. 223-227.

Infograph (2012). www.infograph.com.jo (January 2012).

iSpringSolutions (2012). iSpring Pro Narration Editor. http://www.ispringsolutions.com/help/index.jsp?topic=/pro.6/de sktop/narration.html (January 2012).

Karrer, T. (2007). Understanding E-Learning 2.0. The American Society for Training and Developmet (ASTD): http://www.astd.org/LC/2007/0707_karrer.htm (January 2012)

Katterfeld, C., König, G. (2008). Analysis of e-learning software and guidelines for quality assurance in photogrammetry, remote sensing and GIS. Int. Arch. of Photogrammetry, Remote Sensing and Spatial Information Science, 36(6), 65-70.

Moodle (2011). Installing Moodle. (Moodle) http://docs.moodle.org/20/en/Installing_Moodle (November 2011)

Moodle (2012). www.moodle.com (January 2012)

Technologies, C. f. (2011). Directory of Learning \& Performance Tools. http://c4lpt.co.uk/directory-of-learningperformance-tools/ (January 2012).

TechSmith. (2010). Camtasia Studio Help Guide. http://assets.techsmith.com/docs/pdf-

camtasiaStudio/Create_Engaging_Screencasts.pdf 2012).

Trivantis. (2010). Lectora Inspire e-Learning Software Wins 5 Awards in its First Year. http://www.trivantis.com/lectorainspire-e-learning-software-wins-5-awards-its-first-year (December 2011).

Verishow (2012). www.verishow.com (January 2012).

Wikipedia (2011). www.wikipedia.org (January 2012). 